\title{
Risk factors for lymph node metastasis in early gastric cancer patients: Report from Eastern Europe country- Lithuania
}

\author{
Rimantas Bausys ${ }^{1,2}$, Augustinas Bausys ${ }^{1,2^{*}}$, Indre Vysniauskaite ${ }^{3}$, Kazimieras Maneikis ${ }^{2}$, Dalius Klimas²,
} Martynas Luksta ${ }^{4}$, Kestutis Strupas ${ }^{2,4}$ and Eugenijus Stratilatovas ${ }^{1,2}$

\begin{abstract}
Background: Current risk factors for lymph node metastasis in early gastric cancer have been primarily determined in Asian countries; however their applicability to Western nations is under discussion. The aim of our study was to identify risk factors associated with lymph node metastasis in Western cohort patients from the Eastern European country - Lithuania.

Methods: A total of 218 patients who underwent open gastrectomy for early gastric cancer were included in this retrospective study. After histolopathological examination, risk factors for lymph node metastasis were evaluated. Overall survival was evaluated and factors associated with long-term outcomes were analyzed.

Results: Lymph node metastases were present in 19.7\% of early gastric cancer cases. The rates were 5/99 (4.95\%) for pT1a tumors and 38/119 (31.9\%) for pT1b tumors. Submucosal tumor invasion, lymphovascular invasion, and high grade tumor differentiation were identified as independent risk factors for lymph node metastasis. Submucosal tumor invasion and lymphovascular invasion were also associated with worse 5-year survival results.
\end{abstract}

Conclusion: Our study established submucosal tumor invasion, lymphovascular invasion, and high grade tumor differentiation as risk factors for lymph node metastasis.

Keywords: Early gastric cancer, Lymph node metastasis, Risk factors, Mucosal tumor, T1a

\section{Background}

Gastric cancer is one of the leading causes of cancer death worldwide. It is believed that early detection and appropriate treatment can reduce mortality caused by gastric cancer. After the detection of cancer, preoperative disease staging must be performed to plan an ideal treatment for each individual patient. Next, the absence or presence of lymph node metastasis (LNM) must be confirmed to apply the treatment strategy. Lymph node status has great significance to the path of care chosen in early gastric cancer (EGC). It is not only important for proper treatment, but also for the prognosis of survival $[1,2]$. Additionally, confirmation of LNM is crucial

\footnotetext{
* Correspondence: abpelikanas@gmail.com

'Department of Abdominal Surgery and Oncology, National Cancer Institute, Santariskiu str. 1, Vilnius 08660, Lithuania

${ }^{2}$ Faculty of Medicine, Vilnius University, Ciurlionio str. 21, Vilnius 03101, Lithuania

Full list of author information is available at the end of the article
}

when an endoscopic approach is considered, because such a procedure does not cure the disease in lymph nodes. One obstacle in determining lymph node status has been the uncertainty of radiological tests. Staging of gastric cancer typically utilizes a variety of imaging modalities, such as computed tomography $(\mathrm{CT})$, magnetic resonance imaging (MRI), endoscopic ultrasounds and combined positron tomography, as well as, laparoscopic staging and cytogenetic analysis of peritoneal fluid in appropriate patients $[3,4]$. The evaluation of metastatic infiltration of lymph nodes is mostly based on CT and MRI imaging. However, neither have the correct high sensitivity and specificity for the detection of LNM in gastric cancer $[5,6]$. The lack of accurate radiological imaging calls for research of risk factors for LNM in EGC, which are used when endoscopic treatments of EGC are considered. According to the European Society for Medical Oncology (ESMO) guidelines, gastric 
adenocarcinomas staged as T1a, well-differentiated, less than $2 \mathrm{~cm}$ diameter and not ulcerated have very low or no risks for LNM. Those that fall under such standard criteria are eligible for endoscopic mucosal resection (EMR)/ endoscopic submucosal dissection (ESD) [7-10]. These guidelines are based on known risk factors for LNM, which have been determined in Asia. However, recently published data has revealed race as an independent risk factor for LNM, raising concern whether such risk factors can be considered in Western countries [11, 12].

The aim of our study was to integrate our experience of treating early gastric cancer with open gastrectomy to identify risk factors for LNM in EGC in Western populations.

\section{Methods}

This retrospective study included 218 patients who underwent surgical treatment for EGC in the Department of General and Abdominal Surgery and Oncology, National Cancer Institute, Vilnius, Lithuania between January 2005 and December 2015. In total, 1654 patients with gastric adenocarcinoma were operated on at the institution during the study period. 1436 (86,8\%) patients underwent surgery for advanced gastric cancer and $218(13,2 \%)$ for EGC.EGC was defined as a cancer that does not invade past the submucosa, irrespective of regional lymph node metastasis (T1 any N). None of the patients received neoadjuvant chemotherapy or radiotherapy prior to surgery. All patients had morphological gastric cancer verification before surgery, except in a few cases when it was not possible due to technical feasibility. Depending on cancer localization in the stomach and histological characteristics of the tumor, the type of surgery - total or subtotal gastrectomy- was determined before the operation. Reconstruction after a total gastrectomy was performed with esophagojejunostomy using a jejunal loop and Braun's side-to-side enteroanastomosis (m.Omega). Reconstruction after subtotal gastrectomy consisted of an antecolic end-toside gastrojejunostomy with Braun's jejunojejunostomy (m.Balfur).The standard lymphanodectomy in our institution was a D2 lymph node dissection and was performed in accordance with the guidelines of the Japanese Research Society for Gastric Cancer. D1 lymphanodectomy was an alternative option based on the surgeon's individual decision. R0 resection was defined as no tumor remaining macroscopically and microscopically, and was achieved in all cases. Specimens' histological examination was performed in the National Center of Pathology, Vilnius, Lithuania. Standard histological examination protocol included entire lesion examination with $5 \mathrm{~mm}$ wide slices. All of the dissected lymph nodes were analyzed, each lymph node was embedded in paraffin, and at least two sections were prepared and visualized. Immunohistochemistry was performed using an anti-podoplanin antibody (D2-40) and CD34 antibody to identify and distinguish the lymphatic endothelium. The rate of LNM was calculated after histological evaluation. Various clinicopathological parameters such as gender, age, primary tumor invasion, tumor differentiation grade, lymphatic and vascular invasion, tumor type according to Lauren classification, ulceration, tumor size and localization were evaluated as possible risk factors for LNM. Analysis of postoperative morbidity and intra-hospital 30 - and 90day mortality rates were performed. Surgical complications were classified by Clavien-Dindo classification.

Outcomes of interest included the overall survival (OS) rates. OS was defined as the duration from the date of surgery to the date of death. Data on survival and death were obtained from Lithuania's Cancer register and Lithuania's death register. The date of the last follow up was 31 December 2016. 6 (2.7\%) patients were lost during the follow-up period. Mean and median followup periods were 68 and 63 months (range from 0 to 142) respectively.

\section{Statistical analysis}

All statistical analyses were conducted using the statistical program SPSS 16.0 (SPSS, Chicago, IL, USA). Clinicopathological characteristics were analyzed by a 2-tailed $t$ test, one-way ANOVA test, Chi-square test, or Fisher exact test. The risk factors found to be significant in univariate analysis were included in subsequent multivariate logistic regression analyses to identify the independent variables associated with lymph node metastasis in patients with gastric cancer. Overall survival was analyzed by the Kaplan-Meier method, and the curves drawn were compared by the log-rank test. Multivariate survival analysis was performed using the Cox proportional-hazards model (hazard ratio and 95\% confidence intervals). In all statistical analyses, a $p$ value of $<0.05$ was considered to be significant.

\section{Results}

From January 2005 to December 2015, 218 patients undergoing total or subtotal gastrectomy for EGC were included in this study. All of the patients were of Caucasoid race. Baseline characteristics of all patients are shown in Table 1.

There were 117 (53.7\%) men and 101 (46.3\%) women, with a mean age of $65.58 \pm 12.33$ years. Total gastrectomy was performed in 38 cases and subtotal gastrectomy in 180 cases. Forty-five of 220 patients had postoperative complications, with four of them lethal. Postoperative mortality and morbidity rates were 1.8 and 
Table 1 Baseline characteristics of all patients

\begin{tabular}{|c|c|c|}
\hline \multicolumn{3}{|l|}{ Variable } \\
\hline \multicolumn{2}{|c|}{ Age (mean $\pm S D$, range) (min.-max. Years) } & $65.58 \pm 12.33(27-88)$ \\
\hline \multicolumn{2}{|l|}{$\mathrm{BMI}$ (mean $\pm \mathrm{SD}$, range) $\left(\mathrm{kg} / \mathrm{m}^{2}\right)$} & $26.31 \pm 5.41$ \\
\hline \multicolumn{2}{|c|}{$\begin{array}{l}\text { Count of retrieved lymph nodes } \\
\text { (mean } \pm \mathrm{SD} \text {, range) (min.-max.) }\end{array}$} & $19.89 \pm 9.69(3-70)$ \\
\hline \multirow[t]{2}{*}{ Gender } & Male & $117(53.7 \%)$ \\
\hline & Female & $101(46.3 \%)$ \\
\hline \multirow[t]{4}{*}{ ASA score } & । & $23(10.6 \%)$ \\
\hline & $\|$ & $105(48.2 \%)$ \\
\hline & III & 87 (39.9\%) \\
\hline & IV & $3(1.4 \%)$ \\
\hline \multirow[t]{3}{*}{ Tumor localization } & Lower third & $79(36.2 \%)$ \\
\hline & Middle third & $125(57.3 \%)$ \\
\hline & Upper third & $14(6.4 \%)$ \\
\hline \multirow[t]{2}{*}{ Tumor invasion } & Mucosal & 99 (45.4\%) \\
\hline & Sub-mucosal & $119(54.6 \%)$ \\
\hline \multirow[t]{2}{*}{ Lymph node status } & Positive & $43(19.7 \%)$ \\
\hline & Negative & $175(80.3 \%)$ \\
\hline \multirow[t]{3}{*}{ Tumor differentiation grade } & G1 & $44(20.2 \%)$ \\
\hline & G2 & $70(32.1 \%)$ \\
\hline & G3 & $104(47.7 \%)$ \\
\hline \multirow[t]{2}{*}{ Type of surgery } & Total gastrectomy & $38(17.4 \%)$ \\
\hline & $\begin{array}{l}\text { Subtotal } \\
\text { gastrectomy }\end{array}$ & $180(82.6 \%)$ \\
\hline \multirow[t]{2}{*}{ Type of lymphanodectomy } & D1 & $23(10.6 \%)$ \\
\hline & D2 & $195(89.4 \%)$ \\
\hline
\end{tabular}

$20.6 \%$ respectively. The vast majority of complications (29 of 45, 64.4\%) were not life threatening and did not require any surgical, endoscopic, or radiological interventions. According to Clavien-Dindo classification they were either grade I or II complications. Grade III complications occurred in 8 cases $(3.6 \%)$, and reoperation was indicated for $5(2.3 \%)$ patients. Complications requiring intensive care unit management (grade IV) were rare -4 cases $(1.8 \%)$. Four patients $(1.8 \%)$ died during the intra-hospital period after postoperative complications had occurred. Causes of death for these patients were as follows. One patient had anastomotic leakage and peritonitis, while three patients died from nonsurgical complications: pulmonary embolism -1 case, pneumonia and sepsis - 1 case and acute cardiovascular insufficiency -1 case. Mean hospitalization time was $17.34 \pm 5.90$ days and mean postoperative period was $13.00 \pm 5.39$ days. 30 day mortality rates were higher when compared to intra-hospital mortality rates and involved $6(2,8 \%)$ cases. Three additional deaths were registered between the 31st and 90th postoperative day. 90 day postoperative mortality rates reached $4.1 \%$.
Higher 90 days mortality rates were associated with elderly age ( $\geq 75$ years; $12.5 \%$ vs $1.2 \%, p=0.010$ ). Other factors such as gender, smoking status, obesity (BMI $>30$ ), ASA score, extent of lymphanodectomy, type of surgery, and tumor localization did not impact mortality rate, $p>0.05$.

Majority of the patients underwent a D2 lymphadenectomy - 195 (89.4\%). The average number of removed lymph nodes was $19.89 \pm 9.69$. After performing histological examination of operative material, LNM were revealed in $43(19.7 \%)$ cases. Factors associated with LNM were evaluated by univariate analysis. There was a significantly higher risk for LNM in tumors with submucosal layer infiltration (compared to mucosal infiltration, $p=0.001$ ), lymphovascular invasion (LV+ vs $\mathrm{LV}-, p=0.001$ ), high grade differentiation (G3 vs G1\&G2, $p=0.047$ ), diffuse or mix type according to Lauren classification (compared to intestinal type, $p=0.012$ ), and diameter exceeding $2 \mathrm{~cm}$ (compared to tumors $\leq 2 \mathrm{~cm}$, $p=0.026$ ). Age, gender, tumor localization, ulceration, and signet ring cell carcinoma had no significance in the presence of LNM (Table 2).

The multivariate analysis showed that submucosal tumor invasion, lymphovascular invasion, and high tumor differentiation grade were independent risk factors for lymph node metastasis (Table 3).

\section{Survival analysis}

5-year overall survival was $83.3 \%$ in patients without LNM and 54.2\% in patients with LNM, $p=0.001$ (Fig. 1). In the univariate analysis, LNM $(\mathrm{p}=0.001)$, higher ASA classification (ASA III/IV $\mathrm{p}=0.001$ ), D1 lymphanodectomy $(p=0.049)$, and lymphovascular invasion $(\mathrm{p}=0.001)$ had a negative effect on 5-year survival (Fig. 2). In multivariate analysis, lymphovascular invasion $(p=0.028$; HR 2.19; 95\% CI 1.08-4.42) and age ( $p=0.020$; HR 1.04; 95\% CI 1.01-1.08) were discovered as independent factors with negative influences on the postoperative overall survival rate.

\section{Discussion}

The definition of EGC was established by the Japanese Gastroenterological Endoscopic Society in 1962, originally characterizing EGC as gastric cancer that invades no deeper than the submucosa regardless of lymph node metastasis. EGC is more commonly diagnosed in Asia compared with Western countries. In Japan, EGC comprises approximately $60 \%$ of all diagnosed gastric cancers, whereas in Western countries the incidence of EGC varies from $10 \%$ to $20 \%$. Such differences could be explained by the presence of more screening programs in Asian countries and also by different interpretations of histological changes. Western pathologists consider 
Table 2 Clinicopathological data of patients with EGC and univariate analysis of risk factors for lymph node metastasis

\begin{tabular}{|c|c|c|c|c|c|}
\hline & & LNM- & LNM+ & $p$ & Odds ratio $(95 \% \mathrm{Cl})$ \\
\hline \multirow[t]{2}{*}{ Gender } & Male & 99 (84.6\%) & $18(15.4 \%)$ & $p=0.090$ & $1.80(0.92-3.55)$ \\
\hline & Female & $76(75.2 \%)$ & $25(24.8 \%)$ & & \\
\hline \multicolumn{2}{|l|}{ Age } & $65.26 \pm 12.17$ & $66.91 \pm 13.03$ & $p=0.433$ & - \\
\hline \multirow[t]{3}{*}{ Tumor localization } & Lower $1 / 3$ & $62(78.5 \%)$ & $17(21.5 \%)$ & $p=0.457$ & - \\
\hline & Middle1/3 & $100(80.0 \%)$ & $25(20.0 \%)$ & & \\
\hline & Upper $1 / 3$ & $13(92.9 \%)$ & $1(7.1 \%)$ & & \\
\hline \multirow[t]{2}{*}{ Tumor invasion } & T1a & 94 (94.9\%) & $5(5.1 \%)$ & $p=0.001$ & $8.82(3.31-23.46)$ \\
\hline & $\mathrm{T} 1 \mathrm{~b}$ & $81(68.1 \%)$ & 38 (31.9\%) & & \\
\hline \multirow[t]{2}{*}{ Tumor differentiation } & $\mathrm{G} 1 \& \mathrm{G} 2$ & $100(87.7 \%)$ & $14(12.3 \%)$ & $p=0.006$ & $2.76(1.36-8.57)$ \\
\hline & G3 & 75 (72.1\%) & $29(22.4 \%)$ & & \\
\hline \multirow[t]{2}{*}{ Lymphovascular invasion } & LV+ & $12(40 \%)$ & $18(60 \%)$ & $p=0.001$ & $9.78(4.20-22.72)$ \\
\hline & LV- & $163(86.7 \%)$ & $25(13.3 \%)$ & & \\
\hline \multirow[t]{2}{*}{ Lauren classification } & Diffuse \& mix & 59 (71.1\%) & $24(28.9 \%)$ & $p=0.012$ & $2.09(1.20-3.64)$ \\
\hline & Intestinal & $106(86.2 \%)$ & $17(13.8 \%)$ & & \\
\hline \multirow[t]{2}{*}{ Tumor size } & $\leq 2 \mathrm{~cm}$ & 91 (86.7\%) & $14(13.3 \%)$ & $p=0.026$ & $2.27(1.12-4.59)$ \\
\hline & $>2 \mathrm{~cm}$ & $83(74.1 \%)$ & $29(25.9 \%)$ & & \\
\hline \multirow[t]{2}{*}{ Ulceration } & Ulcerated & $58(74.4 \%)$ & $20(25.6 \%)$ & $p=0.114$ & $1.73(0.88-3.42)$ \\
\hline & Non-ulcerated & $116(83.5 \%$ & $23(16.5 \%)$ & & \\
\hline \multirow[t]{2}{*}{ Signet ring cell } & Yes & $11(73.3 \%)$ & $4(26.7 \%)$ & $p=0.513$ & $1.46(0.44-4.86)$ \\
\hline & No & $149(80.1 \%)$ & 37 (19.9\%) & & \\
\hline
\end{tabular}

invasion into the lamina propria of the mucosa mandatory characteristics for the diagnosis of carcinoma, whereas nuclear and structural features are more important in Japan. Therefore, EGC lesions diagnosed in Japan are potentially diagnosed as high grade dysplasia in Western countries. This distinction could partly explain the higher incidence of EGC in the Asian population and be responsible for better patient prognoses when compared to Western counterparts [11]. Several studies in Asian countries have declared excellent 5-year survival rates for EGC patients with overall survival exceeding 90\%. Comparatively, our study presents worse results with the 5-year overall survival rate reaching only $77,6 \%$. Since there is a disparity in histological

Table 3 Multivariate analysis of risk factors for lymph node metastasis

\begin{tabular}{lll}
\hline Factor & $p$ value & $\begin{array}{l}\text { Odds Ratio } \\
(95 \% \mathrm{Cl})\end{array}$ \\
\hline $\begin{array}{l}\text { Submucosal tumor } \\
\text { invasion (T1b) }\end{array}$ & $p=0.001$ & $6.55(2.28-18.81)$ \\
$\begin{array}{l}\text { Tumor differentiation } \\
\text { grade G3 }\end{array}$ & $p=0.045$ & $2.01(1.03-14.66)$ \\
$\begin{array}{l}\text { Lymphovascular invasion } \\
\text { Tumor size }>2 \mathrm{~cm}\end{array}$ & $p=0.001$ & $6.06(2.28-16.07)$ \\
$\begin{array}{l}\text { Diffuse type according } \\
\text { to Lauren classification }\end{array}$ & $p=0.155$ & $1.82(0.79-4.19)$ \\
\hline
\end{tabular}

interpretations and a difference in average life expectancy amongst distinct regions, it is difficult to compare data of several studies using the same statistical indicators $[2,13]$. Disagreement between Asian and Western interpretations of pre-cancerous lesions and EGC could also influence results of studies analyzing risk factors and rate of LNM in EGC patients. During the last 5 years, 17 studies investigating factors associated with LNM in EGC were published. Eleven studies came from Asian countries and six from Western countries (Table 4).

Rates of LNM reported in various Asian and Western countries were varying. In Asia LNM rates ranged from $2.8 \%$ to $15.5 \%$ for patients with tumors invading only the mucosal layer $[14,15]$ and from $18.3 \%$ to $56.2 \%$ for patients with tumors invading the submucosal layer $[16,17]$. Respectively, in Western countries, rates of LNM varied from $1.9 \%$ to $16.7 \%$ when the tumor was localized to the mucosa and from $18.2 \%$ to $42.9 \%$ when the tumor invaded the submucosal layer $[17,18]$. Our study results were similar; rates of LNM for patients with $\mathrm{T} 1 \mathrm{a}$ and $\mathrm{T} 1 \mathrm{~b}$ cancer were 5.1 and $22.4 \%$, respectively. Risk factors for LNM determined in various studies were also differing. In Asian studies, the most frequently mentioned factors were depth of invasion (9 of 11 studies), tumor size (7 of 11 studies), and lymphatic or lymphovascular invasion (7 of 11 studies). In Western studies, lymphovascular invasion has been of recent focus in five of six studies with our 


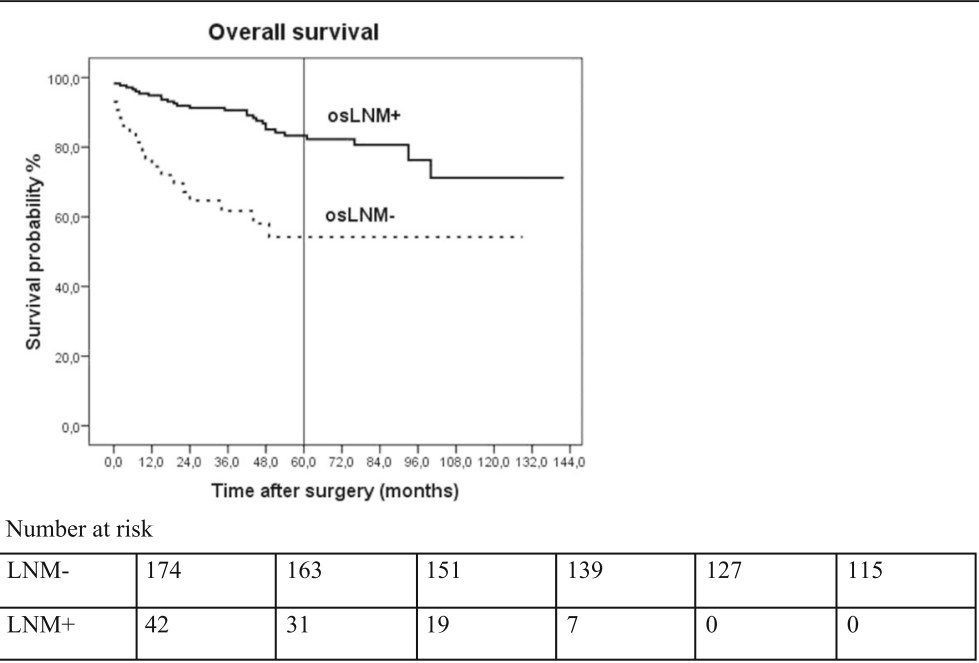

Fig. 1 Five-year overall survival rate of patients with EGC according to lymph node status

results also confirming lymphovascular invasion as a risk factor for LNM. Another risk factor which was studied in our data, submucosal tumor invasion, was mentioned in 3 of 6 previously published Western studies. Tumor differentiation was only mentioned as a risk factor for LMN in reports from Asian nations [15, 17, 19]. To our best knowledge, our study is the first report of Western countries which confirms tumor differentiation as an independent risk factor for LNM. Despite the discussed variation between Asian and Western regions, the use of EMR/ESD as a treatment option for ECG is increasing in the West [8]. Western guidelines such as the National Comprehensive Cancer Network (NCCN) guidelines for gastric cancer treatment and ESMO clinical practice guidelines recommend the endoscopic approach as an appropriate option for some cases of intramucosal gastric cancer. Indications for endoscopic treatment reported by these guidelines are very similar but display several discrepancies. While both guidelines note that tumor diameter should not exceed $2 \mathrm{~cm}$, only the NCCN guidelines indicate lymphovascular invasion as a required criteria. On the other hand, the ESMO guidelines are more strict on the limits for differentiation grade. They suggest that only well differentiated tumors should be treated endoscopically. NCCN guidelines are more liberal by indicating that both well and moderately-well differentiated tumors can be treated by the endoscopic approach. Additionally, ESMO guidelines limit indications with ulceration criteria and NCCN guidelines do not. In our cohort of patients, $30(13.7 \%)$ of 218 patients would have met the criteria for endoscopical treatment according to NCCN guidelines. 1 (3.13\%) of these 30 patients had histologically confirmed LNM. Fewer patients fit ESMO criteria (13 of 218 patients) and none of them had LNM. While LNM risk is low or equal to zero for patients who match standard endoscopical treatment criteria, implementation of expanded criteria in Western countries has been questioned. Furthermore, suspicions about different tumor behavior have increased after Ikoma et al. and Fukuhara et al. studies recently published that race is a risk factor for lymph node metastasis in gastric cancer $[11,12]$.

On the other hand, even non-curative endoscopic treatment could lead to satisfactory results. Hatta et al. recently published a large multi-center study, in which they evaluated and compared long term outcomes for patients who underwent non-curative endoscopic treatment of EGC followed by either radical surgery or only follow-up. The study revealed that patients who underwent radical surgery had significantly longer 3- and 5-year overall survival (OS) and disease-specific survival rates (DSS). However, the difference in DSS rates was rather small (99.4\% vs. 98.7\%) compared to the difference in OS rates (96.7\% vs. $84.0 \%)$. Estimated rates of recurrence were significantly different, although both were low; $1.3 \%$ in the radical surgery group and $3.1 \%$ in the follow-up group. Nonetheless, positive results according to DSS and recurrence rates in the follow-up group should be interpreted carefully due to different clinicopathological backgrounds between the two groups. Some risk factors for LNM (lymphatic invasion or deeper submucosal invasion) were significantly more frequent in the radical surgery group [20]. Furthermore, Nakamura et al. provided a direct correlation between lymphatic infiltration and worse survival [21]. Up to this date, evidence of a correlation between lymphatic invasion and worse survival results have been demonstrated only by studies performed in Asia, with Western studies confirming these findings. Haist et al. analyzed lymphatic invasion and survival result correlation in a Western cohort, however they did not display a significant effect 
A

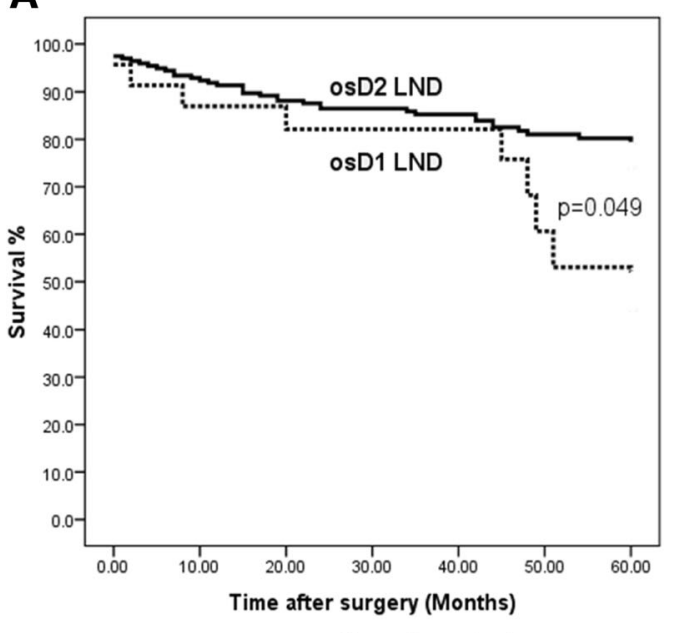

B
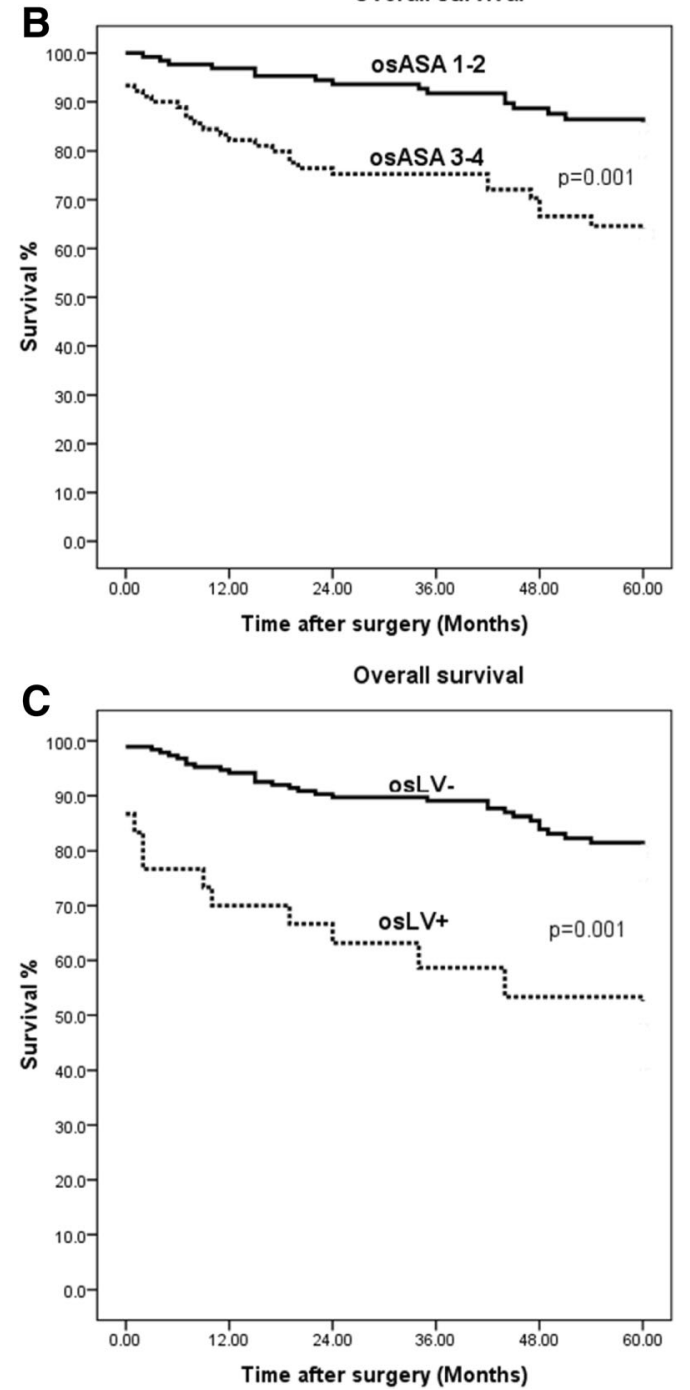

Fig. 2 Five-year overall survival rate of patients with EGC according to lymphanodectomy (a), ASA score (b) and lymphovascular invasion (c) of lymphatic invasion on longtime survival results [22]. Consequently, our study became the first of such Western reports to present lymphovascular invasion as an independent prognostic factor associated with worse longterm survival results.

Several limitations of our study must be taken into consideration. First, it is a retrospective study originating from a single centre conducted over a long period of time. Second, surgical techniques used were not standardized. Even though the D2 lympahadenectomy remained institutionally standard over the entire study period and the number of examined lymph nodes was sufficient, the extent of resection and confirmation of lymph node removal was not clear in every case. Appropriate lymphadenectomy is important because the risk of lymph node metastasis could be underestimated in cases with incomplete lymphanodectomy. However, we believe that the quality of th obtained histological specimens was accurate and adequate, while the average number of removed lymph nodes was $19.89 \pm 9.69$. More than 15 lymph nodes were removed for $72 \%$ of the patients and only $9 \%$ of cases included less than ten dissected lymph nodes. Also, patients with insufficient lymphanodectomy were not excluded from our study to avoid discrepancies as we compared our study results to five other studies from Western countries, where patients with less than 15 examined lymph nodes were included $[18,20,22-$ 24]. Moreover if only patients with $\geq 15$ resected LN would have been analyzed, the percentage of lymph node metastasis would not be much higher than in the whole series (T1a cancer $-5,1 \%$ vs $5,6 \%$, T1b cancer $31,9 \%$ vs $36 \%)$. Therefore, the entire continuous series was used to avoid selection bias. Third, we were unable to use follow-up records, preventing us from estimating and evaluating recurrence rates, disease free survival and disease specific survival. Fourth, although our study was large enough when compared to other similar Western studies, the absolute number of patients with LNM was still relatively low. This reduces the statistical power of our analyses and the confidence of identifying correct risk factors for LNM.

\section{Conclusion}

In our study, LNM occurred in 19,7\% of EGC cases. However, depending on varying criteria of several distinct guidelines, the rate of LNM meeting indications for an endoscopic resection was low or equal to zero. Additionally, this study identified submucosal tumor invasion, lympovascular invasion, and high grade tumor differentiation as risk factors for lymph node metastasis. Lymphatic invasion and submucosal tumor invasion were associated with worse 5-year overall survival results. Endoscopical treatment of EGC should be performed within the standard criteria. If risk factors for 
Table 4 Lymph node metastasis in early gastric cancer - literature review and our results

\begin{tabular}{|c|c|c|c|c|c|c|c|}
\hline Author & Country & Year & \multicolumn{2}{|c|}{$\begin{array}{l}\text { No. of } \\
\text { patients }\end{array}$} & $\begin{array}{l}\mathrm{LNM+} \text { in T1a } \\
\text { cancer patients }\end{array}$ & $\begin{array}{l}\mathrm{LNM+} \text { in T1b } \\
\text { cancer patients }\end{array}$ & Risk factors for LNM \\
\hline \multicolumn{8}{|c|}{ Studies from Asian countries } \\
\hline $\begin{array}{l}\text { Lim MS. } \\
\text { et al. [14] }\end{array}$ & South Korea & 2011 & \multicolumn{2}{|l|}{376} & $2.8 \%$ & $18.4 \%$ & $\begin{array}{l}\text { T1a: tumor size }>2 \mathrm{~cm} \text { and lymphovascular invasion } \\
\text { T1b: macroscopic type (elevated) and lymphovascular } \\
\text { invasion }\end{array}$ \\
\hline $\begin{array}{l}\text { Ren G. el } \\
\text { al. [25] }\end{array}$ & China & 2013 & \multicolumn{2}{|l|}{202} & $9.0 \%$ & $22.5 \%$ & Depth of invasion \\
\hline $\begin{array}{l}\text { Wang L. } \\
\text { et al. [26] }\end{array}$ & China & 2013 & \multicolumn{2}{|l|}{242} & $5.5 \%$ & $20.0 \%$ & Depth of invasion, lymphovascular invasion. \\
\hline $\begin{array}{l}\text { Nakagawa M. } \\
\text { et al. [27] }\end{array}$ & South Korea & 2015 & \multicolumn{2}{|c|}{1042} & Not available & Not available & $\begin{array}{l}\text { Depth of invasion, tumor size, ulceration, age and positive } \\
\text { nodal status by CT. }\end{array}$ \\
\hline Wang Y. [16] & China & 2015 & \multicolumn{2}{|l|}{198} & $6.0 \%$ & $56.2 \%$ & $\begin{array}{l}\text { Depth of invasion. Tumor size. Ulceration. histological type } \\
\text { and venous invasion. }\end{array}$ \\
\hline $\begin{array}{l}\text { Park JH. } \\
\text { et al. [28] }\end{array}$ & South Korea & 2015 & \multicolumn{2}{|c|}{2270} & $2.8 \%$ & $19.0 \%$ & $\begin{array}{l}\text { Depth of invasion, tumor size }>3 \mathrm{~cm} \text { and lymphovascular } \\
\text { invasion }\end{array}$ \\
\hline $\begin{array}{l}\text { Fang WL. } \\
\text { et al. [29] }\end{array}$ & Taiwan & 2015 & \multicolumn{2}{|l|}{391} & $4.9 \%$ & $21.4 \%$ & $\begin{array}{l}\text { T1a: Lauren's diffuse type and lymphatic invasion } \\
\text { T1b: Iymphatic invasion }\end{array}$ \\
\hline $\begin{array}{l}\text { Zhao LY. } \\
\text { et al. [15] }\end{array}$ & China & 2016 & \multicolumn{2}{|l|}{687} & $15.5 \%$ & $35.9 \%$ & $\begin{array}{l}\text { Depth of invasion. tumor size }>2 \mathrm{~cm} \text {, ulceration, } \\
\text { lymphovascular invasion, differentiation }\end{array}$ \\
\hline $\begin{array}{l}\text { Wang YW. } \\
\text { et al. [30] }\end{array}$ & China & 2016 & \multicolumn{2}{|l|}{230} & $8.5 \%$ & $28.6 \%$ & $\begin{array}{l}\text { Depth of invasion, tumor size } \geq 2 \mathrm{~cm} \text { and P53 } \\
\text { overexpression }\end{array}$ \\
\hline $\begin{array}{l}\text { Sekiguchi M. } \\
\text { et al. [19] }\end{array}$ & Japan & 2016 & \multicolumn{2}{|c|}{3131} & $4.2 \%$ & $20.2 \%$ & $\begin{array}{l}\text { Depth of invasion, tumor size } \geq 2 \mathrm{~cm} \text {, ulceration, } \\
\text { lymphovascular invasion, differentiation }\end{array}$ \\
\hline $\begin{array}{l}\text { Zheng Z. } \\
\text { et al. [17] }\end{array}$ & China & 2016 & \multicolumn{2}{|l|}{597} & $3.0 \%$ & $18.3 \%$ & $\begin{array}{l}\text { Depth of invasion, ulceration, lymphovascular invasion, } \\
\text { age, differentiation. }\end{array}$ \\
\hline \multicolumn{8}{|c|}{ Studies from Western countries } \\
\hline $\begin{array}{l}\text { Milhomem LM. } \\
\text { et al. [31] }\end{array}$ & Brazil & 2012 & 126 & $7.8 \%$ & $22.6 \%$ & \multicolumn{2}{|c|}{ Depth of invasion, tumor size $>5 \mathrm{~cm}$, ulceration and lymphatic invasion. } \\
\hline $\begin{array}{l}\text { Bravo Neto GP. } \\
\text { et al. [23] }\end{array}$ & Brazil & 2014 & 26 & $16.7 \%$ & $42.9 \%$ & \multicolumn{2}{|l|}{ Not available } \\
\hline $\begin{array}{l}\text { Fukuhara S. } \\
\text { et al. [10] }\end{array}$ & USA & 2014 & 104 & $7.1 \%$ & $35.4 \%$ & \multicolumn{2}{|c|}{ Lymphovascular invasion, non-Asian race and younger age. } \\
\hline $\begin{array}{l}\text { Haist T. } \\
\text { et al. [22] }\end{array}$ & Germany & 2016 & 124 & $1.9 \%$ & $22.5 \%$ & \multicolumn{2}{|c|}{ Depth of invasion, lymphovascular invasion. } \\
\hline $\begin{array}{l}\text { Ahmad R. } \\
\text { et al. [18] }\end{array}$ & USA & 2016 & 67 & $4.3 \%$ & $31.8 \%$ & \multicolumn{2}{|c|}{ Lymphovascular invasion and positive nodal status by endoscopic ultrasound. } \\
\hline $\begin{array}{l}\text { Ronellenfitsch U. } \\
\text { et al. [24] }\end{array}$ & Germany & 2016 & 275 & $3.9 \%$ & $18.2 \%$ & \multicolumn{2}{|c|}{$\begin{array}{l}\text { Depth of invasion, lymphovascular invasion, diffuse- and mixed-type according } \\
\text { to Lauren. }\end{array}$} \\
\hline Our study & Lithuania & 2017 & 218 & $5.1 \%$ & $31.9 \%$ & \multicolumn{2}{|c|}{ Depth of invasion, lymphovascular invasion and tumor differentiation grade } \\
\hline \multicolumn{8}{|c|}{ Indication for endoscopic treatment of EGC according to different guidelines } \\
\hline $\begin{array}{l}\text { ESMO-ESSO- } \\
\text { ESTRO }\end{array}$ & \multicolumn{7}{|c|}{ Well-differentiated, lesion is $\leq 2 \mathrm{~cm}$ in diameter, confined to the mucosa and not ulcerated. } \\
\hline NCCN & \multicolumn{7}{|c|}{$\begin{array}{l}\text { Well or moderately well differentiated, lesion is } \leq 2 \mathrm{~cm} \text { in diameter, confined to the mucosa, does not exhibit lymphovascular } \\
\text { invasion }\end{array}$} \\
\hline
\end{tabular}

LNM are present in histological specimens, surgery with adequate lymphadenectomy should be followed. To successfully utilize the endoscopical approach in Western countries, criteria need to be expanded and applied to the appropriate population. For safe implementation, further research should be conducted by Western studies.

\section{Acknowledgements}

Not applicable.

Funding

This study was performed without funding.

\section{Availability of data and materials}

The datasets used and analyzed during the current study available from the corresponding author on reasonable request. 


\section{Authors' contributions}

$\mathrm{RB}$ and $\mathrm{ES}$ were guarantor of the integrity of the study. $A B$ was responsible for literature research. DK, KM, IV and ML were responsible for data collection and statistical analysis. Manuscript was prepared by AB and IV, edited by RB and reviewed by ES and KS. All authors read and approved the final manuscript.

\section{Ethics approval and consent to participate}

Ethics approval and consent to participate was given by institutional Bioethical committee.

\section{Consent for publication}

Not applicable.

\section{Competing interests}

The authors declare that they have no competing interests.

\section{Publisher's Note}

Springer Nature remains neutral with regard to jurisdictional claims in published maps and institutional affiliations.

\section{Author details}

'Department of Abdominal Surgery and Oncology, National Cancer Institute, Santariskiu str. 1, Vilnius 08660, Lithuania. ${ }^{2}$ Faculty of Medicine, Vilnius University, Ciurlionio str. 21, Vilnius 03101, Lithuania. ${ }^{3}$ School of Medicine, Georgetown University, Washington, D.C., USA. ${ }^{4}$ Center of Abdominal surgery, Vilnius University Hospital Santaros Klinikos, Santariskiu str. 2 Washington 08661, USA

Received: 2 July 2017 Accepted: 14 November 2017

Published online: 23 November 2017

\section{References}

1. Baušys A, Klimas D, Kilius A, Pauža K, Rudinskaite G, Samalavičius N, et al. Tumor differentiation is a risk factor for lymph node metastasis in patients with gastric cancer. Ann Oncol. 2015;26(suppl 4):iv28.

2. Roviello F, Rossi S, Marrelli D, Pedrazzani C, Corso G, Vindigni C, et al. Number of lymph node metastases and its prognostic significance in early gastric cancer: a multicenter Italian study. J Surg Oncol. 2006;94(4):275-80.

3. Nakahara K, Tsuruta O, Tateishi H, Arima N, Takeda J, Toyonaga A, et al. Extended indication criteria for endoscopic mucosal resection of early gastric cancer with special reference to lymph node metastasisexamination by multivariate analysis. Kurume Med J. 2004;51(1):9-14.

4. Hopkins S, Yang GY. FDG PET imaging in the staging and management of gastric cancer. J Gastrointest Oncol. 2011;2(1):39-44.

5. Hallinan JTPD, Venkatesh SK. Gastric carcinoma: imaging diagnosis, staging and assessment of treatment response. Cancer Imaging Off Publ Int Cancer Imaging Soc. 2013;13:212-27.

6. Hasbahceci M, Akcakaya A, Memmi N, Turkmen I, Cipe G, Yildiz P, et al. Diffusion MRI on lymph node staging of gastric adenocarcinoma. Quant Imaging Med Surg. 2015;5(3):392-400.

7. Soetikno R, Kaltenbach T, Yeh R, Gotoda T. Endoscopic mucosal resection for early cancers of the upper gastrointestinal tract. J Clin Oncol Off J Am Soc Clin Oncol. 2005;23(20):4490-8.

8. Gotoda T. Endoscopic resection of early gastric cancer. Gastric Cancer Off J Int Gastric Cancer Assoc Jpn Gastric Cancer Assoc. 2007;10(1):1-11.

9. Gotoda T, Yanagisawa A, Sasako M, Ono H, Nakanishi Y, Shimoda T, et al. Incidence of lymph node metastasis from early gastric cancer: estimation with a large number of cases at two large centers. Gastric Cancer Off J Int Gastric Cancer Assoc Jpn Gastric Cancer Assoc. 2000;3(4):219-25.

10. Yamaguchi N, Isomoto H, Fukuda E, Ikeda K, Nishiyama H, Akiyama M, et al. Clinical outcomes of endoscopic submucosal dissection for early gastric cancer by indication criteria. Digestion. 2009;80(3):173-81.

11. Fukuhara S, Yabe M, Montgomery MM, Itagaki S, Brower ST, Karpeh MS. Race/ ethnicity is predictive of lymph node status in patients with early gastric cancer. J Gastrointest Surg Off J Soc Surg Aliment Tract. 2014;18(10):1744-51.

12. Ikoma N, Blum M, Chiang Y-J, Estrella JS, Roy-Chowdhuri S, Fournier K, et al. Race is a risk for lymph node metastasis in patients with gastric cancer. Ann Surg Oncol. 2017;24(4):960-5.

13. Suzuki H, Oda I, Abe S, Sekiguchi M, Nonaka S, Yoshinaga S, et al. Clinical outcomes of early gastric cancer patients after noncurative endoscopic submucosal dissection in a large consecutive patient series. Gastric Cancer. 2016. [Epub ahead of print].

14. Lim MS, Lee H-W, Im H, Kim BS, Lee MY, Jeon JY, et al. Predictable factors for lymph node metastasis in early gastric cancer-analysis of single institutional experience. J Gastrointest Surg Off J Soc Surg Aliment Tract. 2011;15(10):1783-8

15. Zhao L-Y, Yin Y, Li X, Zhu C-J, Wang Y-G, Chen X-L, et al. A nomogram composed of clinicopathologic features and preoperative serum tumor markers to predict lymph node metastasis in early gastric cancer patients. Oncotarget. 2016;7(37):59630-39.

16. Wang $Y$. The predictive factors for lymph node metastasis in early gastric cancer: a clinical study. Pak J Med Sci. 2015;31(6):1437-40.

17. Zheng Z, Zhang Y, Zhang L, Li Z, Wu X, Liu Y, et al. A nomogram for predicting the likelihood of lymph node metastasis in early gastric patients. BMC Cancer. 2015;16:92

18. Ahmad R, Setia N, Schmidt BH, Hong TS, Wo JY, Kwak EL, et al. Predictors of lymph node metastasis in western early gastric cancer. J Gastrointest Surg Off J Soc Surg Aliment Tract. 2016;20(3):531-8.

19. Sekiguchi M, Oda I, Taniguchi H, Suzuki H, Morita S, Fukagawa T, et al. Risk stratification and predictive risk-scoring model for lymph node metastasis in early gastric cancer. J Gastroenterol. 2016;51(10):961-70.

20. Hatta W, Gotoda T, Oyama T, Kawata N, Takahashi A, Yoshifuku Y, et al. Is radical surgery necessary in all patients who do not meet the curative criteria for endoscopic submucosal dissection in early gastric cancer? A multi-center retrospective study in Japan. J Gastroenterol. 2017:52(2):175-84.

21. Nakamura $Y$, Yasuoka $H$, Tsujimoto $M$, et al. Importance of lymph vessels in gastric cancer: a prognostic indicator in general and a predictor for lymph node metastasis in early stage cancer. J Clin Pathol. 2006;59:77-82.

22. Haist T, Pritzer H, Pauthner M, Fisseler-Eckhoff A, Lorenz D. Prognostic risk factors of early gastric cancer-a western experience. Langenbecks Arch Surg Dtsch Ges Für Chir. 2016;401(5):667-76.

23. Bravo Neto GP, dos Santos EG, Victer FC, Carvalho CE de S. Lymph node metastasis in early gastric cancer. Rev Colégio Bras Cir 2014; 41(1):11-7.

24. Ronellenfitsch U, Lippert C, Grobholz R, Lang S, Post S, Kähler G, et al. Histology-based prediction of lymph node metastases in early gastric cancer as decision guidance for endoscopic resection. Oncotarget. 2016; 7(9):10676-83.

25. Ren G, Cai R, Zhang W-J, Ou J-M, Jin Y-N, Li W-H. Prediction of risk factors for lymph node metastasis in early gastric cancer. World J Gastroenterol. 2013;19(20):3096-107.

26. Wang $L$, Liang $H$, Wang $X$, Wu L, Ding $X$, Liu $H$. Mode of lymph node metastasis in early gastric cancer and risk factors. Zhonghua Wei Chang Wai Ke Za Zhi Chin J Gastrointest Surg. 2013;16(2):147-50.

27. Nakagawa M, Choi YY, An JY, Chung H, Seo SH, Shin HB, et al. Difficulty of predicting the presence of lymph node metastases in patients with clinical early stage gastric cancer: a case control study. BMC Cancer. 2015:15:943.

28. Park JH, Lee SH, Park JM, Park CS, Park KS, Kim ES, et al. Prediction of the indication criteria for endoscopic resection of early gastric cancer. World J Gastroenterol. 2015;21(39):11160-7.

29. Fang $W-L$, Huang $K-H$, Lan $Y-T$, Chen $M-H$, Chao $Y$, Lo S-S, et al. The risk factors of lymph node metastasis in early gastric cancer. Pathol Oncol Res POR. 2015;21(4):941-6.

30. Wang Y-W, Zhu M-L, Wang R-F, Xue W-J, Zhu X-R, Wang L-F, et al. Predictable factors for lymph node metastasis in early gastric cancer analysis of clinicopathologic factors and biological markers. Tumour Biol J Int Soc Oncodevelopmental Biol Med. 2016;37(7):8567-78.

31. Milhomem LM, Cardoso DMM, Mota ED, Fraga-Júnior AC, Martins E, da Mota $\mathrm{OM}$. Frequency and predictive factors related to lymphatic metastasis in early gastric cancer. Arq Bras Cir Dig ABCD Braz Arch Dig Surg. 2012;25(4):235-9. 